\title{
Procedure-oriented University Digital Admissions System under Big Data Environment
}

\author{
Liu Yun \\ Hainan Vocational College Of Political Science And Law, Hainan Haikou 571100, China
}

Keywords: Digital admission; Data analysis; Information graph

\begin{abstract}
In order to solve the current college admission work problems like workload focus, department coordination problems, and low artificial statistical efficiency, on the basis of college admissions requirements analysis, this paper proposes the use of big data to collect admission work data in each link through information system, and real-time generate statistical analysis of information, which will provide a scientific basis for decision makers. The paper analyzes the overall demand of the system, builds system function structure, and uses .net development platform to realize the system. The system running results show that admission propaganda is in place with accurate real-time data statistics, which effectively reduces manual workload and has very strong practicability.
\end{abstract}

Biography: Liu Yun (1984 - ) male, Xinyang, Henan province, associate professor of Hainan Vocational College of Political Science and Law, research direction: education informatization; Fund project: Hainan Province Education Department project "Research and development of digital campus information platform based on CRP (Hjkj2013-57)"

In recent years, due to the shrinking of overall scale of colleges' admission and the increasing ways of students, the admission activities in higher vocational colleges face enormous difficulties. Many cast archives in higher vocational colleges is far lower than the number of plans, and some even face the embarrassment of no applicants. Faced with this dilemma, professor Zhou Minjuan etc. [1] proposed a series of solutions to "accurately position students market, and scientifically work out schemes for admission". Tsinghua University Yang Rui [2] thinks "college admissions departments accumulated data hiding a lot of important information, which is available for data mining to improve college admission counseling and propaganda work, supporting the admissions decisions, and adjusting the admission plan and professional distribution". Shen Wei [3] using data warehouse and data mining technology, designed an admissions decision data warehouse, and implemented the analysis of structure and loss of students' enrollment. Yang Zhenyu [4] combined data processing technologies such as ADO, SQL for different provinces admission data formats, built an admissions data collection and analysis platform, and achieved rapid transformation and unified data standard of provincial enrollment data as well as real-time online new enrollment statistics and analysis. Mu Lili [5] etc. from the perspective of admission propaganda, thinks that "the choice of university admission propaganda ways greatly affects the competitiveness of the school", and puts forward a complete college enrollment system construction plan based on public cloud computing platform and Micro blog public platform. But the above relevant solutions based on enrollment data are studied from the perspective of a single application, and the overall demand, technical architecture and running mode for college admissions remain to be further discussed.

Therefore, based on the analysis of the requirements of admission process management in colleges and universities, the paper puts forward procedure-oriented digital enrollment system of colleges and universities, and studies system architecture, operation process and key technology, and realizes the system, thus provides corresponding technical support for college enrollment work. 


\section{MANAGEMENT REQUIREMENTS FOR PROCEDURE-ORIENTED COLLEGE ENROLLMENT PROCESS}

Tsinghua University Dr Yin Hao said: in the era of big data, data is not only a collection object, or a kind of basic resources. The data resources can be coordinated to solve many problems in many other fields [6]. This new big data thinking brings new development opportunities for solving the university admissions dilemma. Admission work usually includes process links: pro-phase planning, admission propaganda, admissions, orientation and registration. The data generated by related information system in links is called enrollment data. Enrollment data generated in each process has valuable information for management decision of admissions work, which mainly includes:

(1) Admission propaganda process. The admission propaganda usually locates in the front of the whole process of admission in time, and the process generally uses online information such as websites to release its basic information, admissions policies and other information, and provide online communication, answering questions, etc. for all browsers. Data such as visitor location, visitors flow rate, clicks, online answering questions produced in this process are of value for the lock on admission, propaganda target range, enrollment plan adjustment, staff performance management, etc.

(2) Admissions process. Admission work data mainly come from all provinces' enrollment data, which contains candidates' basic personal information. This information is essential to the subsequent orientation work. Admission propaganda system can in turn provide customized information, and make targeted deploy of the admission related preparation in advance such as teaching, learning and logistics and others.

(3) Orientation propaganda process. Orientation propaganda is similar to admission propaganda, and its main job is to make the admitted students understand the services provided by the school. The biggest difference from the admission propaganda is that propaganda object target range is determined and its propaganda effect has important influence on freshmen registration rate. The application process subsystem may produce visitor traffic and traffic information, which is conducive to optimization adjustment of the next round orientation propaganda work.

(4) Freshmen registration process. This process mainly produces newcomers' registering rate, dropout rate, and drop out reasons, etc. These data requires higher timeliness and accuracy, and the real-time accurate data is able to reflect the new problems in the work in time, facilitates decision makers to adjust quickly, and to provide scientific basis for the establishment of enrollment plan for the coming year.

However, due to management idea, capital, technology and other factors, many colleges and universities information construction is difficult to cover entire admissions process, and the existing relevant sub-information systems are independent of each other. It is difficult to exchange data between subsystems, which greatly restricts the analysis application of the overall enrollment data. Each step's admission information system must be integrated, therefore, to provide a unified accurate and real-time data analysis results for management, provide concise, effective work platform for admissions staff, and provide personalized custom services for students.

\section{THE MAIN RESEARCH PROBLEMS}

System should possess functions like admission propaganda, orientation propaganda, newcomers' registration and real-time statistical analysis and others, which both propagandizes college admission related new information, and makes summary analysis on information got in each link of admission. Therefore, in system design and implementation process, the main problems are of the following several aspects:

A. Cross-platform access

China Internet network information center (CNNIC) in Beijing issued the $36^{\text {th }}$ China Internet Network Development State Statistic Report: till June 2015, there were 594 million mobile Internet users in China, which was an increase of 36.79 million comparing to December 2014. Mobile Internet population proportion increased to $88.9 \%$ from $85.8 \%$ in December 2014. With the bigger 
of mobile terminals and the improving of mobile application experience, the trend of smart phones using as users main Internet terminal becomes further clear [3]. Thus, target users (students and parents) mostly use mobile terminal in visiting subsystems like foreign admission propaganda and interactions with students. To this end, the system user interface must achieve cross-platform uniform access.

\section{B. Unified data presentation}

Some basic information about school in admission propaganda, such as: school situation, departments, professionals, and faculty, is not only a part of admission information, this information may also be present in the school and other foreign websites. And to ensure that the above information is accurate and unified, avoid visitors' misunderstandings, one must get a unified data source to avoid artificial.

\section{Data fusion}

The initial data of admission comes from test board information, but the packet content is limited, with only the candidate's information. To facilitate later orientation work, we need to fuse the data with college related data to facilitate the late development of relevant subsystems.

\section{SYSTEM DESIGN}

\section{A. System architecture design}

The architecture of the system is mainly composed of data resources, resource acquisition layer, business process layer, and user layer, which is shown in Figure 1.

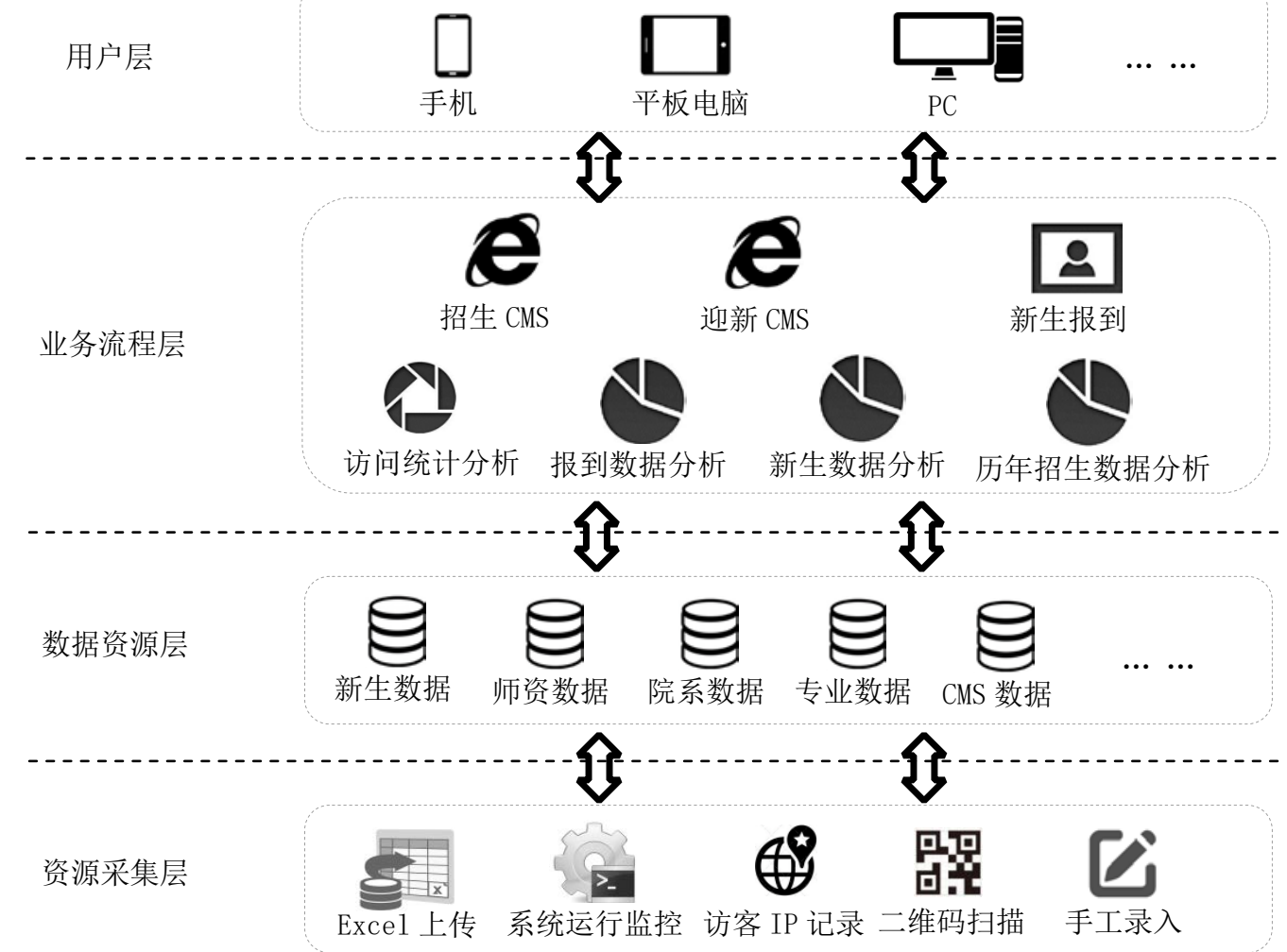

Figure 1 System architecture diagram

Resource acquisition layer: through excel upload, qr code scanning, system operation monitoring, visitor IP records, manual entry and other technical means to achieve each link's data acquisition and pre-processing in the process of admission.

Data resource layer: this layer involves all kinds of resources in the process of recruiting, which includes: foundation data like freshman enrollment data and college teaching faculty professional, and data resources such as propaganda CMS.

Business process layer: under the support of data resource layer, according to the management requirements of each link in the admission process, provide all kinds of application subsystems, including B/S systems: admission CMS, orientation CMS, freshman enrollment APP, system access 
statistics analysis, freshman enrollment data real-time analysis, freshman data statistical analysis, previous enrollment data statistical analysis.

User layer: this layer is mainly to provide users with interactive interface, including all kinds of intelligent terminal equipment and personal computers which can use browser to access the Internet.

B. System function design

System is mainly for the real-time data acquisition, management and statistical analysis of enrollment links such as admission propaganda, admission, freshman register, to optimize and upgrade the admission management process. Each link's subsystem design is as follows:

First is admission propaganda subsystem. Use CMS management admission propaganda information to release information to the users in form of web portal. System background has data acquisition functions such as traffic statistics and visitor IP record.

Second is freshman registration subsystem. Based on HTML 5 standard and Ajax development mode, use .net development environment. Front-end systems use responsive design patterns, and freshman can use mobile phones and other intelligent terminals access to the system. Register the enrollment report, drop out report and other relevant data through qr code scanning and manual entry and other functions.

Third is orientation propaganda subsystem. Based on B/S system developed by .net, system seamless docks CRP data center and provides data upload interface, so administrators can upload the enrollment data to college CRP data center. System can read freshman counselors, faculty, and professional in existing data in the CRP data center. New students can log in system by name and ID number to get personalized custom information such as his counselors, faculty profession, countrymen, students and others.

Fourth is statistics and analysis subsystem. Statistical analysis is divided into three parts. One is the real-time statistical analysis report data of freshman registration, including: registration number, not registration number, drop out number, reasons for not registration or drop out, and registration rate, etc. Second is the statistical analysis report of freshman registration relevant data, including: sex ratio, enrollment number in birthplace, political affiliation, and age structure. Three is past enrollment data statistical analysis, including: provincial registration rate, acceptance rate and enrollment number. These provide decision-making basis for next year’s admission work.

\section{SYSTEM IMPLEMENTATION}

According to system function, the implementation of this system includes the realization of subsystems like admission information network, orientation information network, new registration entry, freshman registration statistics, freshman data statistics, enrollment data analysis, and website access statistics.

A. Admissions information network

Admissions information CMS is based on HTML 5 standards and its front end uses responsive design patterns. Use CSS3 media queries and design multiple website styles, so the users can have a good browsing experience through different terminals. 

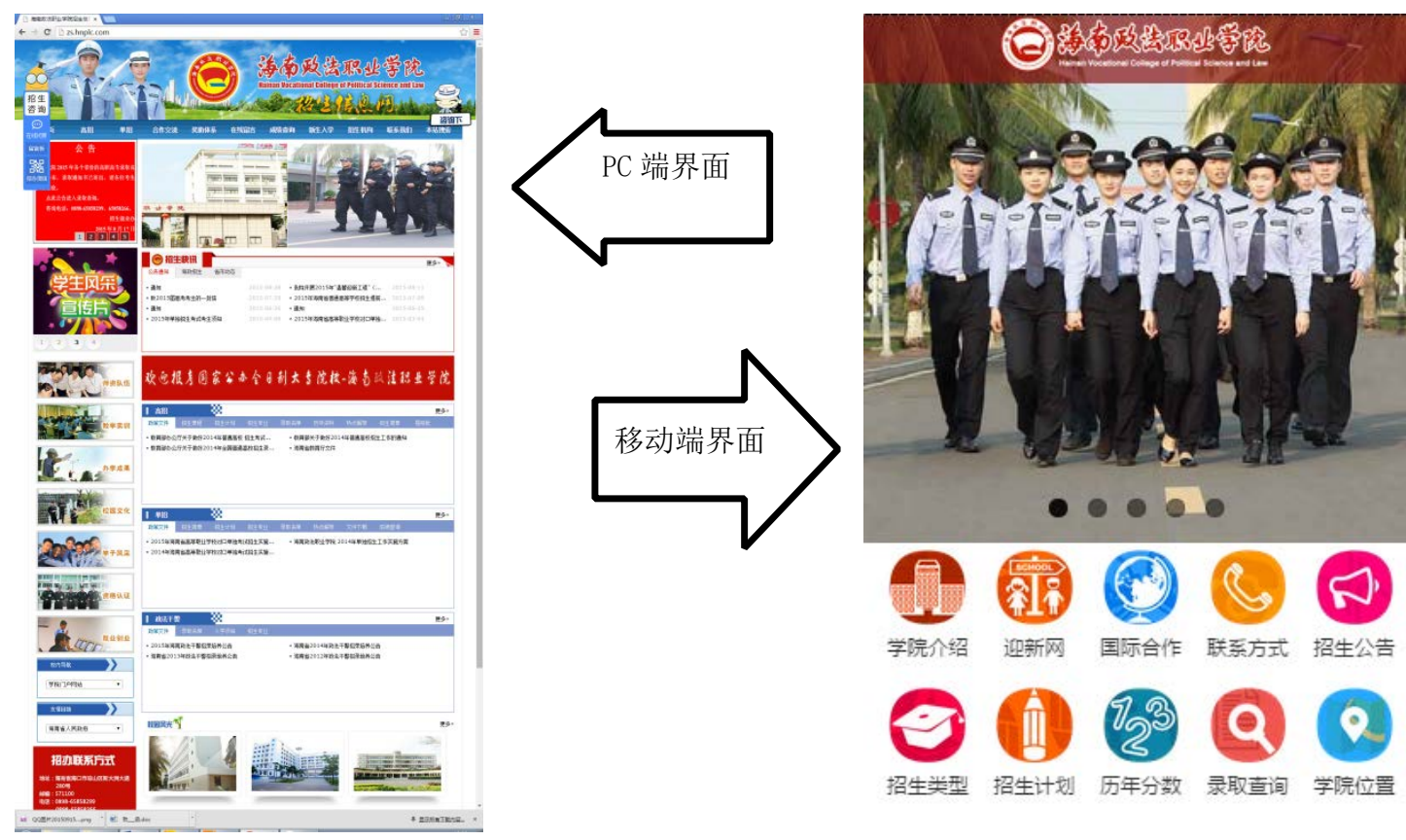

Figure 2 Admissions information network function interface

\section{B. Orientation information network}

Based on .net development, user authentication information comes from admissions data. Use name and ID number as system log in credentials. This system provides counselor, departments and professionals, countrymen, classmate to authentic users, and the data is from CRP data center multi-table view, which is shown in Figure 3:
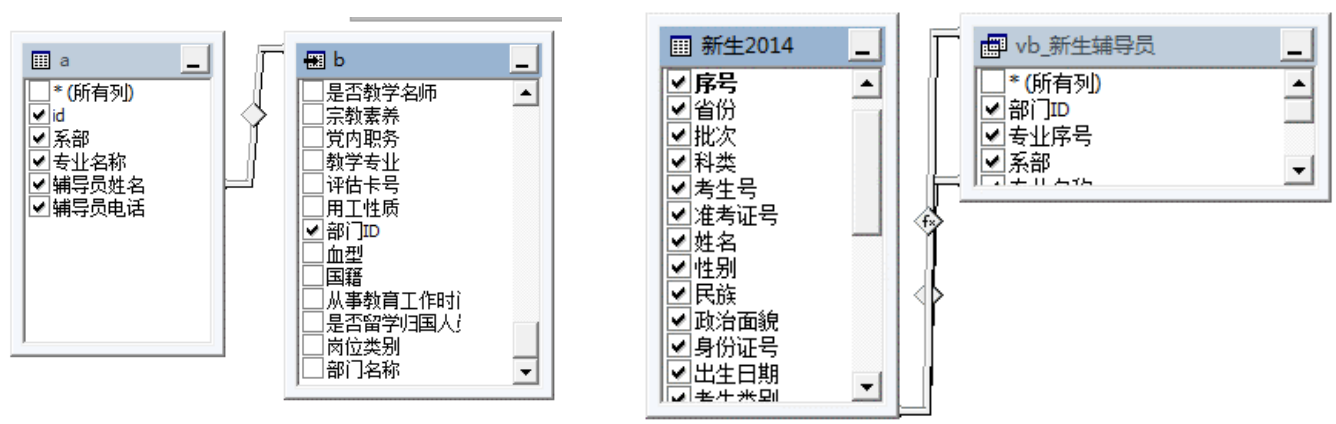

Figure 3 Orientation data view

\section{Freshman registration entry}

To reduce the pressure of the server, the system adopts RIA development idea. Use Ajax development mode, chooses asp development language in server side, and use HTML + CSS $3+$ javascript in front end. System operation interface and key code are shown in Figure 4:

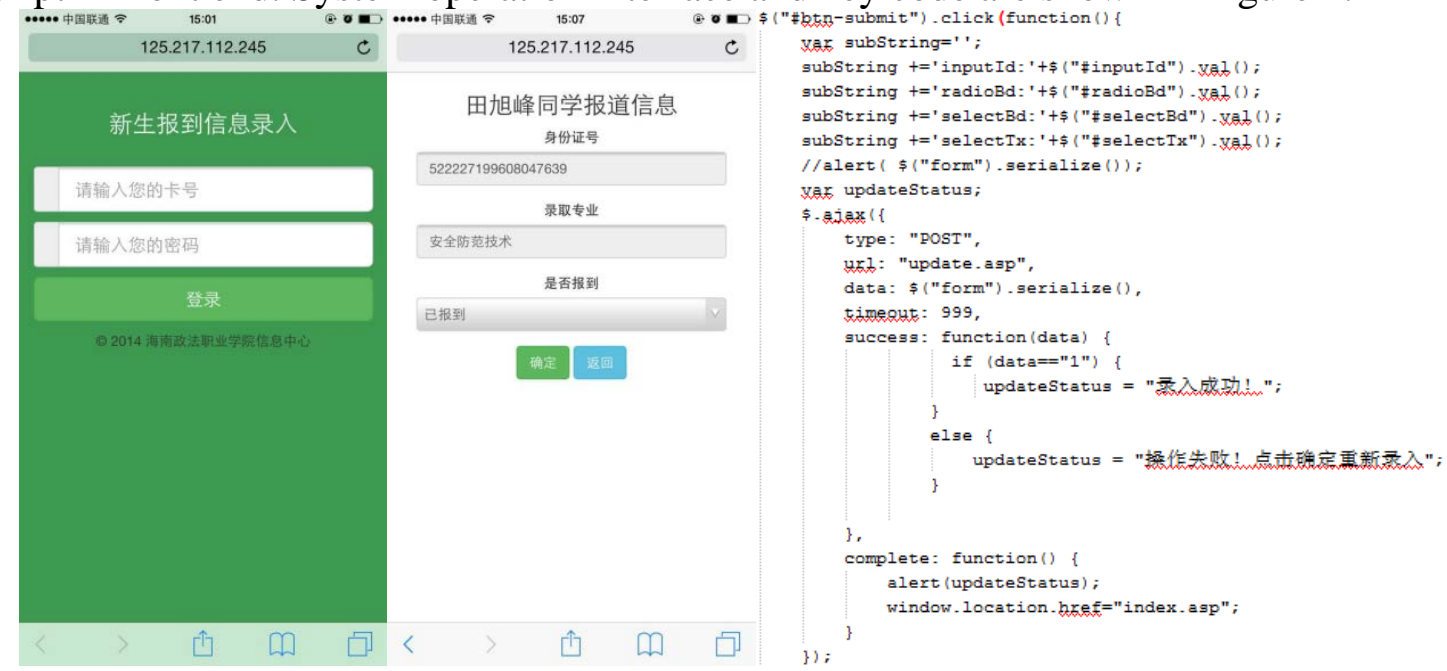

Figure 4 Freshman registration input subsystem 


\section{Freshman registration statistics}

System uses ASP to develop multiple data services to put forward requests in data center, and the query results are packed as JSON format. System front-end uses Javascript to parse JSON data, and displays in the form of charts and statistical figures. System operation interface and key code are shown in Figure 5:

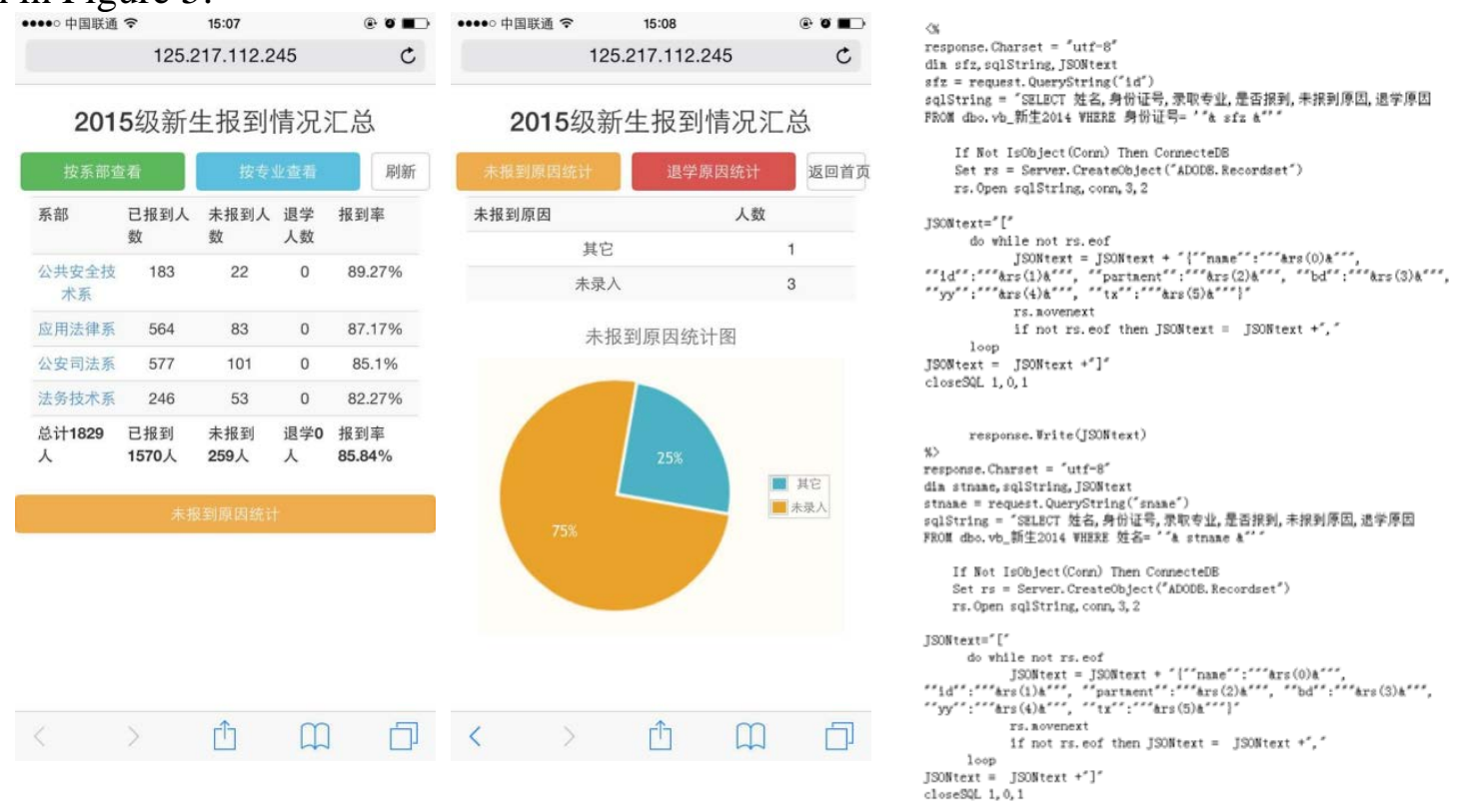

Figure 5 Freshman registration statistical system

\section{E. Freshman data statistics}

Use ASP development data service to process all kinds of statistical query requests in data center such as sex, province, political affiliation, age and others, and the query results are encapsulated as JSON data format. The front end applies jqplot drawing control to render JSON data into information chart. System operation interface and key codes are shown in Figure 6:

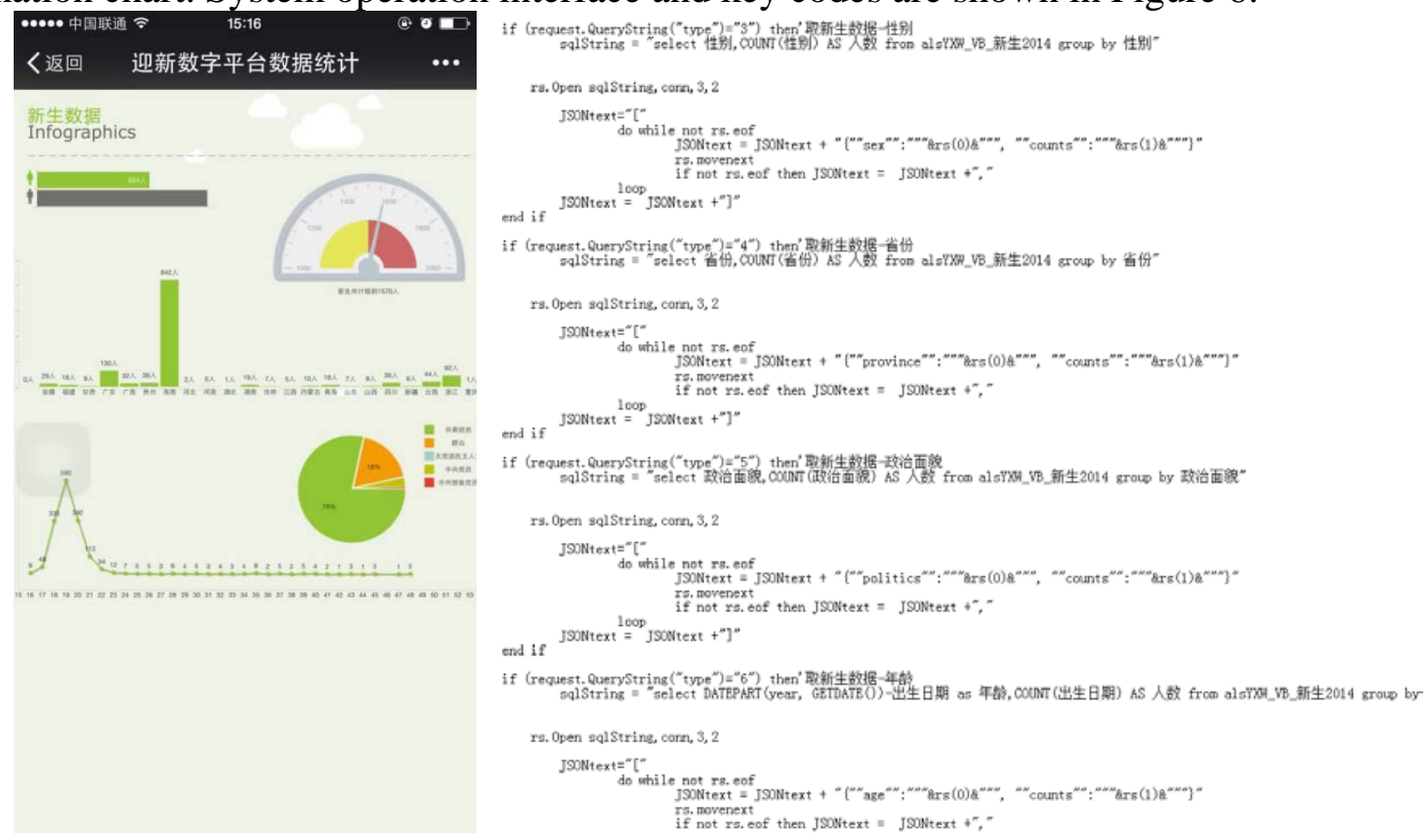

\section{F. Admission data analysis}

Figure 6 Freshman statistics subsystem

Use .net to develop multiple data service components to send statistical query request to data center such as acceptance rate, registration rate, registration number and others, then package the query results got from data center as JSON format data. The front end applies jqplot drawing control to render the JSON data as information chart. System operation interface and key codes are 
as shown in Figure 7:

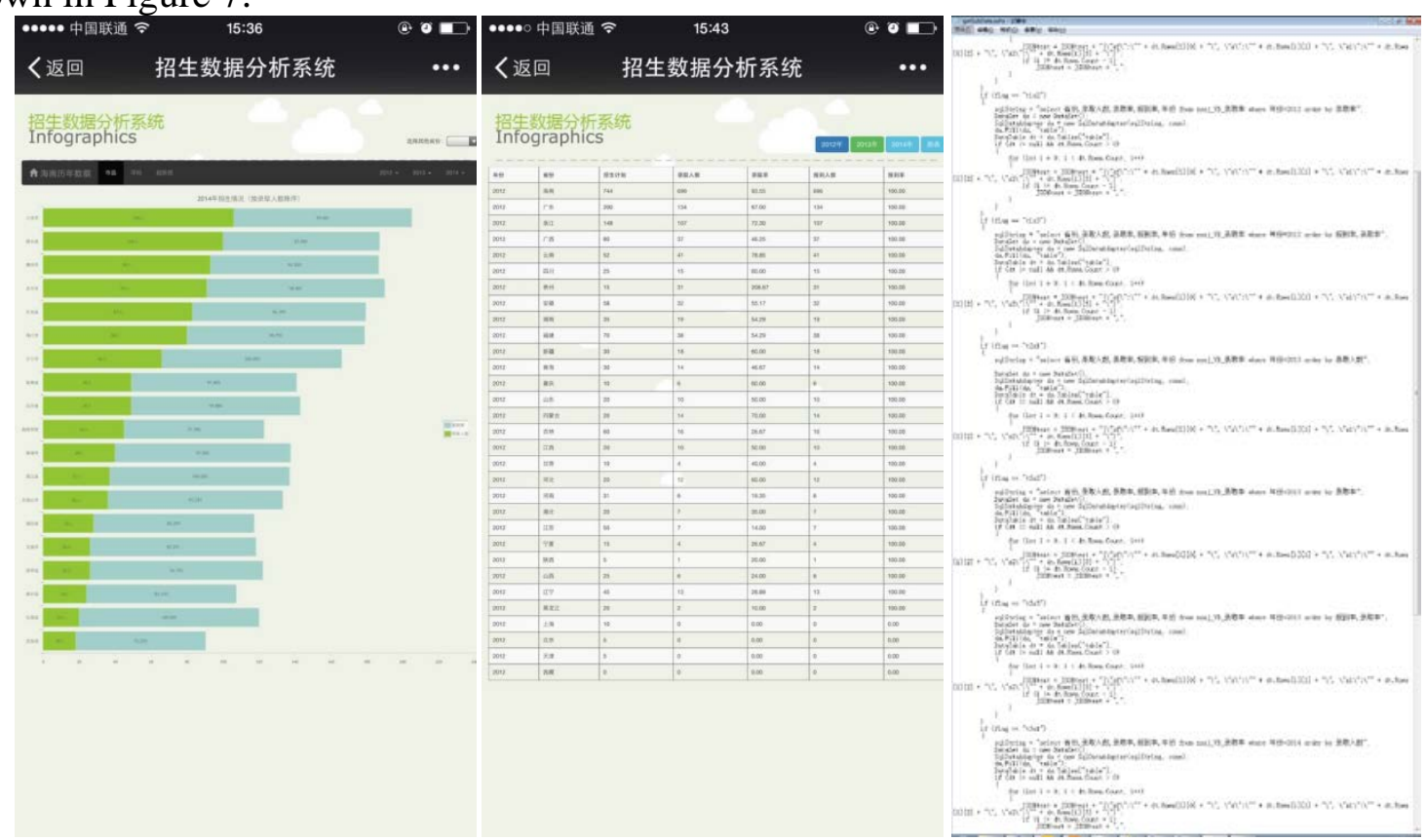

G. Site access statistics

Figure 7 Admission data analysis subsystem

Front end uses HighCharts chart control to render the information got from statistics data component as information chart. System operation interface and key codes are shown in Figure 8:

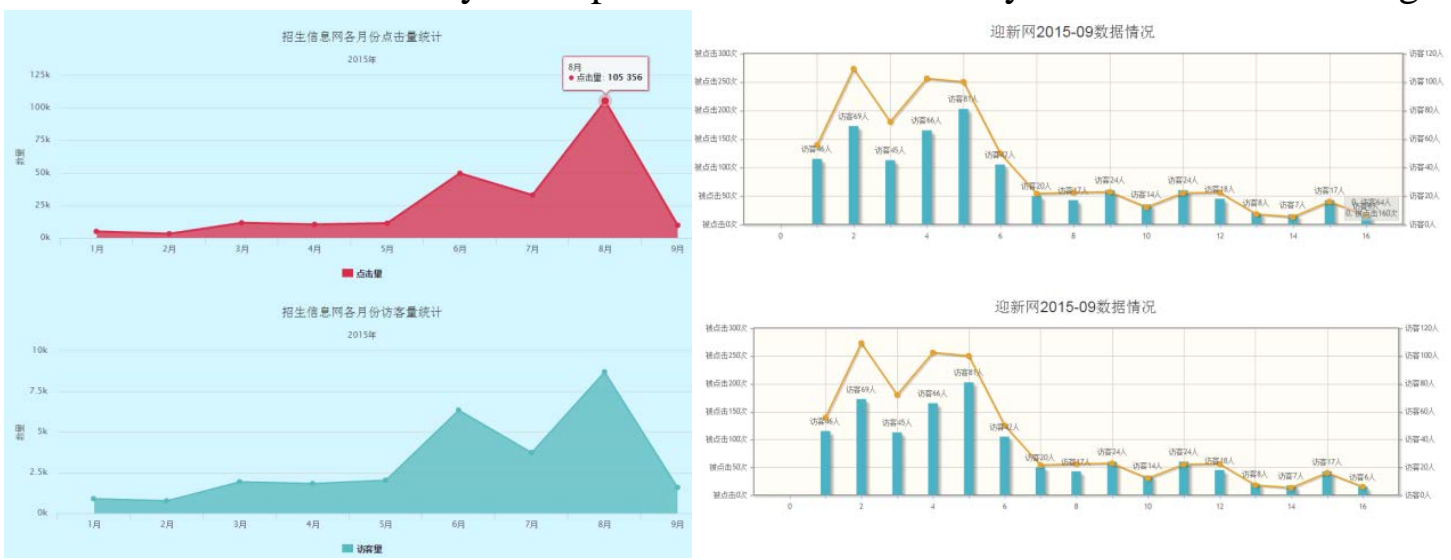

Figure 8 Run results of website visiting statistics

\section{CONCLUSION}

Based on college enrollment management demands, this paper puts forward a process-oriented digital admission system based on data collection analysis, analyzes the overall implementation approach of the system, designs system architecture, and uses .net development platform to realize the system. Since 2014 when the system was put in use, the running effect has been good. The rising acceptance rate and registration rate in the past two years has proved the system's practical application value.

\section{FUNDS}

Hainan Province Education Department project "Research and development of digital campus information platform based on CRP (Hjkj2013-57)"

\section{REFERENCES:}

[1] Zhou Minjuan, Wang ling, Li Lizeng. Higher vocational colleges enrollment difficulties and 
countermeasures study under the new situation. [J] Journal of Shijiazhuang Railway Vocational and Technical College. 2013 (22) : 41-45

[2] Yang Yue, Guo Dayong. Application foreground of data mining in university admission work [J]. Journal of Education Science. 2007 (5) : 66-68

[3] Shen Wei. Higher vocational colleges admissions decisions warehouse design and implementation based on data mining technology. [J] Journal of Network Security Technology and Application. 2015 (3) : 165-167

[4] Yang Zhenyu. The design and implementation of college enrollment data acquisition and analysis system [J]. Journal of Software, 2015 (5) : 61-66

[5] Mu Lili, Liu Shuyan. College enrollment system practice study based on cloud computing and Micro blog public platform [J]. Modern Computers (professional edition). 2015 (16) : 60-63

[6] Yin Hao, Qiao Bo. Big data driven network information plane research [J]. Journal of Computers. 2015 (3) : 1-15

[7] CNNIC. 2013-2014 China mobile Internet investigation report [EB/OL]. http://www.cnnic.net.cn/hlwfzyj /hlwxzbg/hlwtjbg/201507/t20150722_52624.htm. July 22, 2015.

Author introduction: 